\title{
Amine reactivity with charged sulfuric acid clusters
}

\author{
B. R. Bzdek, D. P. Ridge, and M. V. Johnston \\ Department of Chemistry and Biochemistry, University of Delaware, Newark, DE, USA
}

Received: 18 April 2011 - Published in Atmos. Chem. Phys. Discuss.: 12 May 2011

Revised: 2 August 2011 - Accepted: 14 August - Published: 26 August 2011

\begin{abstract}
The distribution of charged species produced by electrospray of an ammonium sulfate solution in both positive and negative polarities is examined using Fourier transform ion cyclotron resonance mass spectrometry (FTICRMS). Positively-charged ammonium bisulfate cluster composition differs significantly from negatively-charged cluster composition. For positively-charged clusters all sulfuric acid is neutralized to bisulfate, whereas for negatively-charged clusters the degree of sulfuric acid neutralization is cluster size-dependent. With increasing cluster size (and, therefore, a decreasing role of charge), both positively- and negativelycharged cluster compositions converge toward ammonium bisulfate. The reactivity of negatively-charged sulfuric acid-ammonia clusters with dimethylamine and ammonia is also investigated by FTICR-MS. Two series of negativelycharged clusters are investigated: $\left[\left(\mathrm{HSO}_{4}\right)\left(\mathrm{H}_{2} \mathrm{SO}_{4}\right)_{\mathrm{x}}\right]^{-}$and $\left[\left(\mathrm{NH}_{4}\right)_{\mathrm{x}}\left(\mathrm{HSO}_{4}\right)_{\mathrm{x}+1}\left(\mathrm{H}_{2} \mathrm{SO}_{4}\right)_{3}\right]^{-}$. Dimethylamine substitution for ammonia in $\left[\left(\mathrm{NH}_{4}\right)_{\mathrm{x}}\left(\mathrm{HSO}_{4}\right)_{\mathrm{x}+1}\left(\mathrm{H}_{2} \mathrm{SO}_{4}\right)_{3}\right]^{-}$clusters is nearly collision-limited, and subsequent addition of dimethylamine to neutralize $\mathrm{H}_{2} \mathrm{SO}_{4}$ to bisulfate is within one order of magnitude of the substitution rate. Dimethylamine addition to $\left[\left(\mathrm{HSO}_{4}\right)\left(\mathrm{H}_{2} \mathrm{SO}_{4}\right)_{\mathrm{x}}\right]^{-}$clusters is either not observed or very slow. The results of this study indicate that amine chemistry will be evident and important only in large ambient negative ions $(>m / z 400)$, whereas amine chemistry may be evident in small ambient positive ions. Addition of ammonia to unneutralized clusters occurs at a rate that is $\sim 2-3$ orders of magnitude slower than incorporation of dimethylamine either by substitution or addition. Therefore, in locations where amine levels are within a few orders of magnitude of ammonia levels, amine chemistry may compete favorably with ammonia chemistry.
\end{abstract}

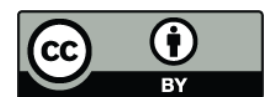

Correspondence to: M. V. Johnston (mvj@udel.edu)

\section{Introduction}

The process of forming small clusters from gas-phase molecules and their subsequent growth to a size where they may serve as cloud condensation nuclei (CCN) and thereby affect global climate is poorly understood. One reason for this uncertainty is that particle formation occurs in the $1 \mathrm{~nm}$ diameter size range, whereas aerosols are activated to serve as $\mathrm{CCN}$ around $100 \mathrm{~nm}$ diameter. Growth from the nucleating cluster to the $\mathrm{CCN}$ size range therefore requires a $10^{6}$ fold increase in particle mass. This process may be a significant contributor to global CCN levels (Merikanto et al., 2009). Enhancing our ability to predict aerosol climate effects is critical for a better quantitative understanding of the contributors to radiative forcing (Solomon et al., 2007). A better understanding of aerosol climate effects requires improved capability in prediction of ambient $\mathrm{CCN}$ levels under varying conditions (Kuang et al., 2010; Spracklen et al., 2008). Such predictive capability necessitates a mechanistic understanding of new particle formation.

The early steps of particle formation and growth have recently attracted much scientific interest (Bzdek and Johnston, 2010). In particular, amines have emerged as potentially significant contributors to these processes. This interest is due in part to the observation of amines during the growth of newly nucleated particles (Smith et al., 2010, 2008; Makela et al., 2001). Additionally, computational studies predict particulate amine levels may be enhanced relative to ammonia, despite the much lower atmospheric concentrations of amines (Barsanti et al., 2009; Kurtén et al., 2008). Recent experimental studies of nucleation have observed an enhancement in the ternary nucleation rate in the presence of amines (Berndt et al., 2010; Erupe et al., 2011). Amines have also been shown to contribute to particle growth (Wang et al., 2010a, b; Qiu et al., 2011). We have determined the kinetics and thermodynamics of amine substitution for ammonia in positively-charged ammonium salt clusters of a wide

Published by Copernicus Publications on behalf of the European Geosciences Union. 
array of sizes (Bzdek et al., 2010a, b, 2011). Regardless of the type of salt, amine substitution is nearly collision-limited on the cluster surface, which implies that small (1-2 nm diameter) ambient salts are likely to be aminium salts rather than ammonium salts, even if they were initially nucleated as ammonium salts.

Most recently, advances in ambient aerosol measurement instrumentation have permitted composition measurements of uncharged and charged molecular clusters. In the cluster chemical ionization mass spectrometer (cluster-CIMS), ambient uncharged clusters are ionized by charge transfer from a reagent ion (Zhao et al., 2010). Clusters containing sulfuric acid are preferentially ionized by imparting a negative charge to them. The atmospheric pressure interface time-of-flight mass spectrometer (APi-TOF) samples ambient ions through an atmospheric pressure interface into a high resolution TOF mass analyzer (Junninen et al., 2010). Both of these methods ultimately perform mass analysis on a charged molecular cluster, whether that charge is intentionally imparted to the cluster (cluster-CIMS) or is naturally occurring (APi-TOF). However, the effect of charge on the composition of small molecular clusters is poorly understood.

This work examines the types of cluster distributions produced from electrospray ionization of ammonium sulfate and dimethylammonium sulfate solutions in both positive and negative polarity. The differences in cluster composition due to the polarity of charge, as well as their implications in terms of ambient measurements of molecular clusters, are discussed. Additionally, we determine both the kinetics of dimethylamine substitution for ammonia in negatively-charged ammonium bisulfate clusters and the kinetics of dimethylamine addition to these clusters in order to predict the composition of salt clusters likely to be present among ambient negative ions. Dimethylamine is used as a model amine because it is frequently observed in high abundance in the air (Ge et al., 2011) and has also been observed in newly nucleated nanoparticles during new particle formation (Makela et al., 2001; Smith et al., 2010). In previous work, we examined reactions of positively-charged ammonium bisulfate clusters with monomethylamine and trimethylamine as well as with dimethylamine and observed that the chemistry was very similar regardless of the type of amine (Bzdek et al., 2010a). The results of this work will facilitate interpretation of the mass spectra of ambient molecular clusters, as well as improve our understanding of the chemistry and composition of ca. 1-2 $\mathrm{nm}$ diameter particles.

\section{Experimental section}

The experimental setup is similar to that used in our previous work on positively-charged bisulfate, nitrate, and methanesulfonate clusters (Bzdek et al., 2010a, b, 2011). Charged ammonium bisulfate clusters were introduced into a 7T Bruker apex-Qe Fourier transform ion cyclotron res- onance mass spectrometer (FTICR-MS) by electrospray of an ammonium sulfate (Aldrich) solution in 50/50 water/methanol. Charged dimethylammonium bisulfate clusters were produced by electrospray of a dimethylammonium sulfate solution made by combining solutions of dimethylamine (Fluka) in 50/50 methanol/water and $\mathrm{H}_{2} \mathrm{SO}_{4}$ (Fisher) in 50/50 methanol/water. For broadband spectra, the solution concentration was $0.05 \mathrm{M}$, whereas for kinetics experiments a $1.0 \mathrm{mM}$ solution was used.

Electrospray produced an array of clusters. For kinetics experiments, a specific cluster was isolated by mass selection and accumulation in a quadrupole. Ions were then transferred to the ICR cell where they were exposed to a constant pressure of reactant gas (dimethylamine: $2.4 \pm 0.5 \times 10^{-8}$ torr; ammonia: $1.0 \pm 0.2 \times 10^{-7}$ torr; Matheson Tri-Gas) that was introduced to the cell via a leak valve. Measurement of the reactant gas pressure inside the ICR cell is described in Bzdek et al. (2010a). Negatively-charged ammonium bisulfate clusters were exposed to dimethylamine gas in order to determine the kinetics of both substitution for ammonia and addition of dimethylamine to the clusters. Ammonium bisulfate clusters were also exposed to ammonia gas to determine the kinetics of ammonia addition to the clusters. Electrospray of a dimethylammonium sulfate solution in negative mode produced complicated spectra due to substitution by sodium for dimethylamine. Negatively-charged dimethylammonium bisulfate clusters were unstable upon mass selection; therefore, no kinetic data were obtained for exposure of these clusters to dimethylamine or ammonia gas.

A mass spectrum of ions in the ICR cell can be obtained at a specific trapping time. FTICR-MS provides high resolving power and high accuracy mass-to-charge $(\mathrm{m} / \mathrm{z}$ ) measurements, allowing for the assignment of unique elemental formulae to reactant and product ions. A plot of ion abundance as a function of trapping time (reaction profile) reveals the progress of the sequential reactions. In some of the more exothermic reactions, the reactant molecule induces a more complicated decomposition rather than substitution alone. A sensitivity analysis was performed in order to elucidate the effect of the decomposition pathways on measured kinetics (Bzdek et al., 2011). In the model, cluster decomposition was assumed to decrease the total cluster ion intensity by a factor similar to that observed experimentally, typically 20 $30 \%$ over a time period of about $1 \mathrm{~s}$. The model showed that fitting the experimental data without taking cluster decomposition into account gave measured rate constants that were larger than the actual rate constants. Typically, the actual rate constants were about 30-40\% smaller than the measured values for the first or second reaction steps, but there was no difference between measured and actual rate constants for later reaction steps. Based on the measured rate constants in this work, it is unlikely that cluster decomposition significantly affected our kinetic measurements. All data were fit to the kinetic models using the simplex method of non-linear fitting embodied in the Solver function of the Microsoft Excel 

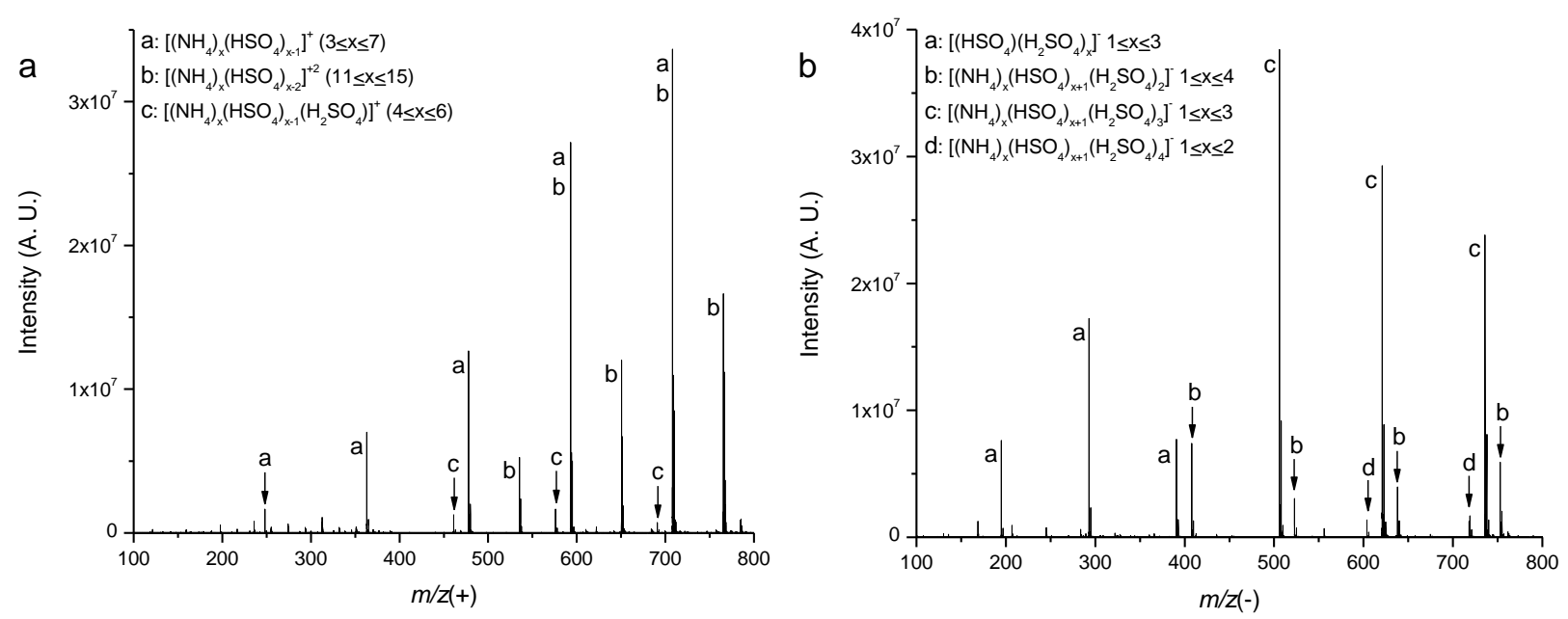

Fig. 1. Electrospray ionization mass spectra of an ammonium sulfate solution in (a) positive and (b) negative modes.

program. Second order rate constants were determined from gas pressure measurements in the ICR cell, as discussed elsewhere (Bzdek et al., 2010a, b); reactive uptake coefficients (reaction probabilities) were determined using capture collision theory to calculate the theoretical collisional rate constant (Ridge, 2003).

\section{Results and discussion}

\subsection{Electrospray of ammonium sulfate and dimethylammonium sulfate solutions}

Although the ions produced during electrospray ionization are not necessarily at equilibrium, the species most likely to receive a charge are those that tend to be more stable upon charging. In complex solutions containing several analytes, some chemical species will receive charge preferentially relative to other species in the same solution (Oss et al., 2010). Similar to this phenomenon, a solution of ammonium sulfate contains ammonium and sulfate ions that, upon ionization and transfer from the liquid phase to the gas phase, produce an array of unique charged clusters that contain differing numbers of ammonium and bisulfate ions. An analysis of the distribution of charged species produced by electrospray of ammonium sulfate can give an indication of the relative stabilities of ammonium sulfate/ammonium bisulfate clusters that may be expected to be observed in ambient air.

Figure 1 provides mass spectra of an ammonium sulfate solution introduced by electrospray into the FTICR-MS operating in (a) positive and (b) negative modes. Interestingly, electrospray of the same solution produces cluster ions of very different composition depending upon polarity. In positive mode, three distinct series of clusters are observed. The first series (indicated in Fig. 1a by the letter "a") con- sists of singly-charged ammonium bisulfate clusters in the form $\left[\left(\mathrm{NH}_{4}\right)_{\mathrm{x}}\left(\mathrm{HSO}_{4}\right)_{\mathrm{x}-1}\right]^{+}$, where all sulfuric acid is neutralized to bisulfate. The second series (indicated in Fig. 1a by the letter "b") is similar to the first series, as all sulfuric acid is neutralized to bisulfate; however, these clusters are doubly-charged and are in the form $\left[\left(\mathrm{NH}_{4}\right)_{\mathrm{x}}\left(\mathrm{HSO}_{4}\right)_{\mathrm{x}-2}\right]^{+2}$. These clusters overall contain one fewer bisulfate ion than the singly-charged clusters, resulting in a +2 charge. The third series (indicated in Fig. 1a by the letter "c") consists of clusters where not all sulfuric acid in the clusters is neutralized to bisulfate. In other words, these clusters are more acidic and can be described as being in the form $\left[\left(\mathrm{NH}_{4}\right)_{\mathrm{x}}\left(\mathrm{HSO}_{4}\right)_{\mathrm{x}-1}\left(\mathrm{H}_{2} \mathrm{SO}_{4}\right)\right]^{+}$.

The three different series of charged clusters observed in positive mode contrast greatly with the charged clusters observed from electrospray of the same solution in negative mode (Fig. 1b). For negative ions, four unique series of charged clusters are observed. The first consists of simple clusters of sulfuric acid and bisulfate (i.e. $\left[\left(\mathrm{HSO}_{4}\right)\left(\mathrm{H}_{2} \mathrm{SO}_{4}\right)_{\mathrm{x}}\right]^{-}$, indicated by the letter "a" in Fig. 1b). The second, third, and fourth cluster series are all ammonium bisulfate clusters with varying degrees of sulfuric acid neutralization to bisulfate. These clusters can be described by $\left[\left(\mathrm{NH}_{4}\right)_{\mathrm{x}}\left(\mathrm{HSO}_{4}\right)_{\mathrm{x}+1}\left(\mathrm{H}_{2} \mathrm{SO}_{4}\right)_{2}\right]^{-}$, $\left[\left(\mathrm{NH}_{4}\right)_{\mathrm{x}}\left(\mathrm{HSO}_{4}\right)_{\mathrm{x}+1}\left(\mathrm{H}_{2} \mathrm{SO}_{4}\right)_{3}\right]^{-}$, and $\left[\left(\mathrm{NH}_{4}\right)_{\mathrm{x}}\left(\mathrm{HSO}_{4}\right)_{\mathrm{x}}+1\right.$ $\left.\left(\mathrm{H}_{2} \mathrm{SO}_{4}\right)_{4}\right]^{-}$(indicated by letters "b", "c", and "d", respectively, in Fig. 1b). These observations suggest that the presence of ammonium is less favorable in small negatively-charged clusters containing sulfuric acid than in small positively-charged clusters. The electrospray distributions are consistent with observations by Hanson and Eisele (2002), who examined similar negatively-charged clusters at atmospheric pressure and found that the number of ammonium ions in the clusters is generally smaller than 

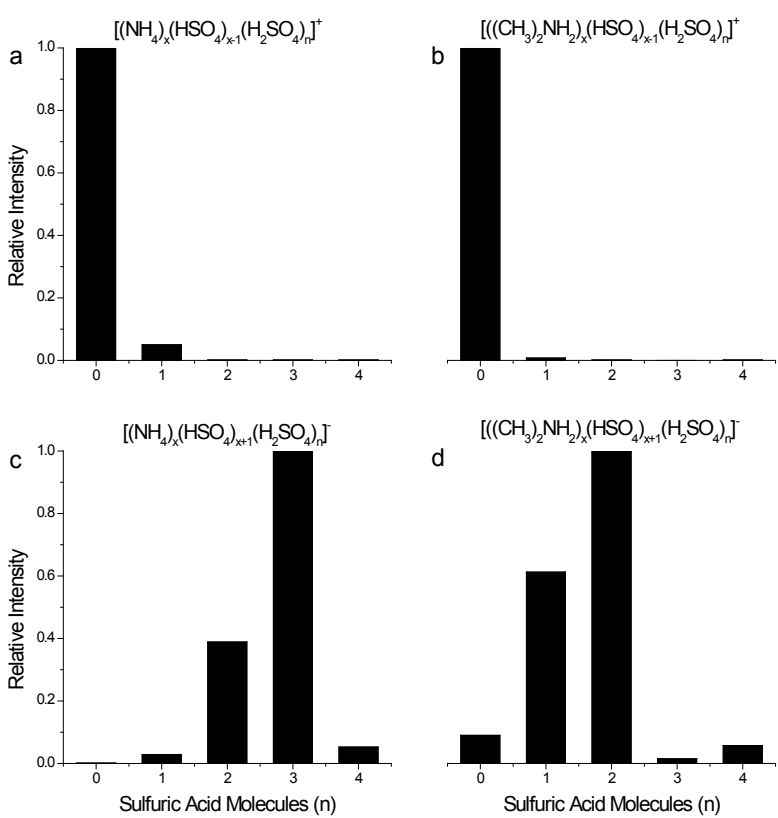

Fig. 2. Cluster acidity (defined as the number of unneutralized sulfuric acid molecules, $n$, in a cluster) for clusters formed through electrospray of ammonium sulfate and dimethylammonium sulfate solutions in positive and negative polarities.

the number of sulfur-containing species (sulfuric acid and bisulfate). In Fig. 1, the effect of charge on cluster composition decreases as the cluster size increases. The corollary to this is that both polarity clusters converge towards the same composition (ammonium bisulfate) at larger cluster size. For instance, for positive ions in Fig. 1, the ammonium:bisulfate ratio decreases with increasing cluster size, whereas for negative ions, the ammonium:bisulfate ratio increases with increasing cluster size and in both cases approaches a 1:1 ratio. It is interesting that ammonium sulfate appears not to be the preferred composition over the range of cluster sizes examined here. However, at much larger particle sizes, ammonium sulfate eventually becomes preferred. For example, the elemental composition of $25 \mathrm{~nm}$ mass normalized diameter ammonium sulfate particles produced by electrospray gives a molar $N / S$ ratio of 2, indicating these particles are composed of ammonium sulfate $(N / S=2)$, rather than ammonium bisulfate $(N / S=1)$ (Zordan et al., 2010).

Figure 2 presents a comparison of cluster acidity (defined as the number of unneutralized sulfuric acid molecules, $n$ ) in positively-charged and negatively-charged ammonium bisulfate and dimethylammonium bisulfate clusters. For a given type of cluster (ammonium bisulfate or dimethylammonium bisulfate) at a given polarity (positive or negative), the relative signal intensities of the different series of ions produced by electrospray are plotted. Note that for positive ions, only singly-charged clusters are considered; for negative ions, only clusters containing ammonium or dimethy- lammonium are considered (sulfuric acid-bisulfate clusters are not included). For positive ions (Fig. 2a-b), clusters tend to be fully neutralized to bisulfate, as for both ammonium bisulfate and dimethylammonium bisulfate clusters the predominant cluster series observed in the mass spectrum is one that contains no unneutralized sulfuric acid $(n=0)$. However, the presence of dimethylammonium appears to enhance neutralization to bisulfate better than the presence of ammonium, as in Fig. 2b there is less signal intensity from the $\left[\left(\left(\mathrm{CH}_{3}\right)_{2} \mathrm{NH}_{2}\right)_{\mathrm{x}}\left(\mathrm{HSO}_{4}\right)_{\mathrm{x}-1}\left(\mathrm{H}_{2} \mathrm{SO}_{4}\right)\right]^{+}$series than from the $\left[\left(\mathrm{NH}_{4}\right)_{\mathrm{x}}\left(\mathrm{HSO}_{4}\right)_{\mathrm{x}+1}\left(\mathrm{H}_{2} \mathrm{SO}_{4}\right)\right]^{+}$series in Fig. 2a. The reason for this enhanced neutralization to bisulfate is likely because dimethylamine is a stronger base than ammonia

Negative ions (Fig. 2c-d) show two interesting phenomena. The first observation is that negative ions in general differ significantly in composition relative to positive ions. The second observation is that the composition of ammonium bisulfate negative ions is different than the composition of dimethylammonium bisulfate negative ions, despite the similarity between the two in positive mode. Specifically, negative ions tend to be much more acidic (fewer sulfuric acid molecules neutralized to bisulfate) than positive ions. Whereas in positive mode the predominant cluster series for both types of clusters contains no unneutralized sulfuric acid $(n=0)$, the most intense series of negatively-charged ammonium bisulfate clusters contains three unneutralized sulfuric acid molecules ( $n=3$; Fig. 2 c) and the most intense series of negatively-charged dimethylammonium bisulfate clusters contains two unneutralized sulfuric acid molecules $(n=2$; Fig. 2d). These observations also indicate that for negativelycharged clusters, dimethylammonium enhances neutralization of sulfuric acid to bisulfate better than ammonium. Again, this can be attributed to dimethylamine's stronger basicity.

The clusters examined in this work are produced by the dissociation of larger, metastable species as they travel to the ICR cell and not simply by charge transfer to a previously neutral cluster (Bzdek et al., 2010b). Nonetheless, the clusters that are eventually trapped in the cell are stable. We have previously examined the stability of these clusters by performing experiments where an isolated cluster is held for varying periods of time in the ICR cell with no reactant gas or with a small pressure of unreactive argon collision gas (Bzdek et al., 2010a) and observed that there was no change in the cluster distribution with time, indicating that trapped clusters are relatively stable under vacuum. Additionally, it should be noted that not all clusters observed in a broadband mass spectrum can be isolated for reactivity studies. One reason for this relates to how these clusters are formed: because these clusters are formed from larger, metastable ions, isolation of a particular ion with sufficient intensity depends on which larger ions are selected in the quadrupole and how those ions dissociate on the way to the ICR cell. Finally, sodium substitution for ammonium or dimethylammonium is frequently observed 
(although significantly more sodium substitution is observed for the dimethylammonium-substituted clusters). Sodium is a ubiquitous contaminant; however these clusters are usually easily ignored, as the experimental method allows one to exclude isolation of the sodium-substituted clusters. Sodiumsubstituted clusters were excluded from further study because they are not atmospherically relevant.

Analysis of the ions produced from electrospray ionization of ammonium sulfate and dimethylammonium sulfate solutions in both positive and negative modes combined with a consideration of the constraints discussed above give an indication of the most likely (most favorable) charged species to be formed. The atmospheric implications resulting from these observations are discussed later.

\subsection{Reactivity of negatively-charged ammonium bisulfate clusters}

In addition to examination of the composition of ions produced by electrospray of an ammonium sulfate solution, we examined the reactivity of these ions. We have previously studied the kinetics and thermodynamics of exposure of positively-charged ammonium bisulfate, ammonium nitrate, and ammonium methanesulfonate clusters to dimethylamine (Bzdek et al., 2010a, b, 2011). These previous studies focused solely on positive ions. Here, we discuss the reactivity of negatively-charged ammonium bisulfate clusters and sulfuric acid-bisulfate clusters upon exposure to dimethylamine gas.

The two series of clusters were analyzed in the kinetics experiments. The first series consisted of the sulfuric acidbisulfate clusters $\left(\left[\left(\mathrm{HSO}_{4}\right)\left(\mathrm{H}_{2} \mathrm{SO}_{4}\right)_{\mathrm{x}}\right]^{-}\right)$, which occurred at low $\mathrm{m} / \mathrm{z}$ values and contained no ammonium. The second series was the most abundant series of negative ions observed and was of the form $\left[\left(\mathrm{NH}_{4}\right)_{\mathrm{x}}\left(\mathrm{HSO}_{4}\right)_{\mathrm{x}+1}\left(\mathrm{H}_{2} \mathrm{SO}_{4}\right)_{3}\right]^{-}$. For these ammonium bisulfate clusters, three specific clusters were isolated and exposed to dimethylamine in order to elucidate the kinetics of amine substitution and amine addition to the cluster: a cluster containing one ammonium ion, $\left[\left(\mathrm{NH}_{4}\right)\left(\mathrm{HSO}_{4}\right)_{2}\left(\mathrm{H}_{2} \mathrm{SO}_{4}\right)_{3}\right]^{-} ;$a cluster containing two ammonium ions, $\left[\left(\mathrm{NH}_{4}\right)_{2}\left(\mathrm{HSO}_{4}\right)_{3}\left(\mathrm{H}_{2} \mathrm{SO}_{4}\right)_{3}\right]^{-}$; and a cluster containing three ammonium ions, $\left[\left(\mathrm{NH}_{4}\right)_{3}\left(\mathrm{HSO}_{4}\right)_{4}\left(\mathrm{H}_{2} \mathrm{SO}_{4}\right)_{3}\right]^{-}$. Two unique chemical reactions occurred upon exposure of these clusters to dimethylamine: (1) dimethylamine substitution for ammonia and (2) dimethylamine addition to the cluster.

The substitution reaction can be described by Scheme 1 . Note that in Scheme 1, the unneutralized sulfuric acid molecules serve essentially as spectators to the reaction.

\section{SCHEME 1}

$$
\begin{aligned}
& {\left[\left(\mathrm{NH}_{4}\right)_{\mathrm{x}}\left(\mathrm{HSO}_{4}\right)_{\mathrm{x}+1}\left(\mathrm{H}_{2} \mathrm{SO}_{4}\right)_{3}\right]^{-}+\left(\mathrm{CH}_{3}\right)_{2} \mathrm{NH} \stackrel{k_{1}}{\longrightarrow}} \\
& {\left[\left(\mathrm{NH}_{4}\right)_{\mathrm{x}-1}\left(\left(\mathrm{CH}_{3}\right)_{2} \mathrm{NH}_{2}\right)\left(\mathrm{HSO}_{4}\right)_{\mathrm{x}+1}\left(\mathrm{H}_{2} \mathrm{SO}_{4}\right)_{3}\right]^{-}+\mathrm{NH}_{3}}
\end{aligned}
$$

$$
\begin{aligned}
& {\left[\left(\mathrm{NH}_{4}\right)_{\mathrm{x}-1}\left(\left(\mathrm{CH}_{3}\right)_{2} \mathrm{NH}_{2}\right)\left(\mathrm{HSO}_{4}\right)_{\mathrm{x}+1}\left(\mathrm{H}_{2} \mathrm{SO}_{4}\right)_{3}\right]^{-}+\left(\mathrm{CH}_{3}\right)_{2} \mathrm{NH}} \\
& \stackrel{k_{2}}{\longrightarrow}\left[\left(\mathrm{NH}_{4}\right)_{\mathrm{x}-2}\left(\left(\mathrm{CH}_{3}\right)_{2} \mathrm{NH}_{2}\right)_{2}\left(\mathrm{HSO}_{4}\right)_{\mathrm{x}+1}\left(\mathrm{H}_{2} \mathrm{SO}_{4}\right)_{3}\right]^{-}+\mathrm{NH}_{3}
\end{aligned}
$$

$\left[\left(\mathrm{NH}_{4}\right)_{\mathrm{x}-2}\left(\left(\mathrm{CH}_{3}\right)_{2} \mathrm{NH}_{2}\right)_{2}\left(\mathrm{HSO}_{4}\right)_{\mathrm{x}+1}\left(\mathrm{H}_{2} \mathrm{SO}_{4}\right)_{3}\right]^{-}+\left(\mathrm{CH}_{3}\right)_{2} \mathrm{NH}$

$\stackrel{k_{3}}{\longrightarrow} \cdots \stackrel{k_{\mathrm{x}}}{\longrightarrow}\left[\left(\left(\mathrm{CH}_{3}\right)_{2} \mathrm{NH}_{2}\right)_{\mathrm{x}}\left(\mathrm{HSO}_{4}\right)_{\mathrm{x}+1}\left(\mathrm{H}_{2} \mathrm{SO}_{4}\right)_{3}\right]^{-}+\mathrm{NH}_{3}$

Scheme 2 describes the addition reaction, whereby a dimethylamine can add to the cluster, effectively neutralizing the sulfuric acid and growing the cluster to a larger size.

\section{SCHEME 2}

$$
\begin{aligned}
& {\left[\left(\left(\mathrm{CH}_{3}\right)_{2} \mathrm{NH}_{2}\right)_{\mathrm{x}}\left(\mathrm{HSO}_{4}\right)_{\mathrm{x}+1}\left(\mathrm{H}_{2} \mathrm{SO}_{4}\right)_{3}\right]^{-}+\left(\mathrm{CH}_{3}\right)_{2} \mathrm{NH} \stackrel{k_{\text {addl }}}{\longrightarrow}} \\
& {\left[\left(\left(\mathrm{CH}_{3}\right)_{2} \mathrm{NH}_{2}\right)_{\mathrm{x}+1}\left(\mathrm{HSO}_{4}\right)_{\mathrm{x}+2}\left(\mathrm{H}_{2} \mathrm{SO}_{4}\right)_{2}\right]^{-}}
\end{aligned}
$$

$$
\begin{aligned}
& {\left[\left(\left(\mathrm{CH}_{3}\right)_{2} \mathrm{NH}_{2}\right)_{\mathrm{x}+1}\left(\mathrm{HSO}_{4}\right)_{\mathrm{x}+2}\left(\mathrm{H}_{2} \mathrm{SO}_{4}\right)_{2}\right]^{-}+\left(\mathrm{CH}_{3}\right)_{2} \mathrm{NH} \stackrel{k_{\mathrm{add} 2}}{\longrightarrow}} \\
& {\left[\left(\left(\mathrm{CH}_{3}\right)_{2} \mathrm{NH}_{2}\right)_{\mathrm{x}+2}\left(\mathrm{HSO}_{4}\right)_{\mathrm{x}+3}\left(\mathrm{H}_{2} \mathrm{SO}_{4}\right)\right]^{-}}
\end{aligned}
$$

$$
\begin{aligned}
& {\left[\left(\left(\mathrm{CH}_{3}\right)_{2} \mathrm{NH}_{2}\right)_{\mathrm{x}+2}\left(\mathrm{HSO}_{4}\right)_{\mathrm{x}+3}\left(\mathrm{H}_{2} \mathrm{SO}_{4}\right)\right]^{-}+\left(\mathrm{CH}_{3}\right)_{2} \mathrm{NH} \stackrel{k_{\text {add }}}{\longrightarrow}} \\
& {\left[\left(\left(\mathrm{CH}_{3}\right)_{2} \mathrm{NH}_{2}\right)_{\mathrm{x}+3}\left(\mathrm{HSO}_{4}\right)_{\mathrm{x}+4}\right]^{-}}
\end{aligned}
$$

The kinetics experiment is similar to our previous work on positive ions (Bzdek et al., 2010a, b, 2011). An ammonium bisulfate cluster is isolated by mass selection in the quadrupole of the mass spectrometer. The isolated cluster is then transferred to the ICR cell, where it is exposed to dimethylamine gas at constant pressure. Reaction time is varied, and time-dependent mass spectra are recorded. A reaction profile is created by plotting the relative abundance of each reaction step against exposure time. Pseudo-first order kinetics applies to these reactions because the pressure of the reactant gas is constant during the experiment. A fit of the reaction profile to pseudo-first order kinetics allows for quantitative determination of the rate constants for the sequential substitution and addition reactions.

Figure 3 presents the reaction profile (symbols) and statistical fit to pseudo-first order kinetics (lines) for $\left[\left(\mathrm{NH}_{4}\right)\left(\mathrm{HSO}_{4}\right)_{2}\left(\mathrm{H}_{2} \mathrm{SO}_{4}\right)_{3}\right]^{-}$exposed to dimethylamine gas. At time $t=0 \mathrm{~s}$, the initial cluster is the predominant ion observed, which is expected as no reaction should have 
Table 1. Pseudo-first order rate constants, second order rate constants, and uptake coefficients for reaction of dimethylamine with negativelycharged ammonium bisulfate clusters*.

\begin{tabular}{lrrrr}
\hline Cluster & $\begin{array}{r}\text { Reaction } \\
\text { step }\end{array}$ & $\begin{array}{r}\text { Pseudo-first order } \\
\text { rate constant }\left(\mathrm{s}^{-1}\right)\end{array}$ & $\begin{array}{r}\text { Second order rate constant } \\
\left(\mathrm{cm}^{3} \text { molecule } \mathrm{s}^{-1}\right)\end{array}$ & $\begin{array}{r}\text { Uptake } \\
\text { coefficient, } \gamma\end{array}$ \\
\hline$\left[\left(\mathrm{HSO}_{4}\right)\left(\mathrm{H}_{2} \mathrm{SO}_{4}\right)\right]^{-}$ & Addition & $<1.1 \times 10^{-5}$ & $<1.3 \times 10^{-14}$ & $<9.7 \times 10^{-6}$ \\
\hline$\left[\left(\mathrm{HSO}_{4}\right)\left(\mathrm{H}_{2} \mathrm{SO}_{4}\right)_{2}\right]^{-}$ & Addition & $1.2 \pm 0.2 \times 10^{-3}$ & $1.4 \pm 0.3 \times 10^{-12}$ & $1.0 \pm 0.3 \times 10^{-3}$ \\
\hline$\left[\left(\mathrm{NH}_{4}\right)\left(\mathrm{HSO}_{4}\right)_{2}\left(\mathrm{H}_{2} \mathrm{SO}_{4}\right)_{3}\right]^{-}$ & Substitution & $0.26 \pm 0.03$ & $3.1 \pm 0.6 \times 10^{-10}$ & $0.24 \pm 0.07$ \\
& Addition 1 & $0.14 \pm 0.01$ & $1.7 \pm 0.3 \times 10^{-10}$ & $0.13 \pm 0.04$ \\
& Addition 2 & $0.11 \pm 0.01$ & $1.3 \pm 0.3 \times 10^{-10}$ & $0.10 \pm 0.03$ \\
& Addition 3 & $2.2 \pm 0.3 \times 10^{-2}$ & $2.6 \pm 0.5 \times 10^{-11}$ & $2.1 \pm 0.6 \times 10^{-2}$ \\
\hline$\left[\left(\mathrm{NH}_{4}\right)_{2}\left(\mathrm{HSO}_{4}\right)_{3}\left(\mathrm{H}_{2} \mathrm{SO}_{4}\right)_{3}\right]^{-}$ & Substitution 1 & $0.48 \pm 0.08$ & $5.6 \pm 1.1 \times 10^{-10}$ & $0.44 \pm 0.13$ \\
& Substitution 2 & $0.38 \pm 0.06$ & $4.5 \pm 0.9 \times 10^{-10}$ & $0.36 \pm 0.11$ \\
& Addition 1 & $0.19 \pm 0.03$ & $2.2 \pm 0.4 \times 10^{-10}$ & $0.17 \pm 0.05$ \\
& Addition 2 & $0.13 \pm 0.02$ & $1.6 \pm 0.3 \times 10^{-10}$ & $0.13 \pm 0.04$ \\
& Addition 3 & $3.6 \pm 0.5 \times 10^{-2}$ & $4.2 \pm 0.8 \times 10^{-11}$ & $3.4 \pm 1.0 \times 10^{-2}$ \\
\hline$\left[\left(\mathrm{NH}_{4}\right)_{3}\left(\mathrm{HSO}_{4}\right)_{4}\left(\mathrm{H}_{2} \mathrm{SO}_{4}\right)_{3}\right]^{-}$ & Substitution 1 & $0.56 \pm 0.06$ & $6.6 \pm 1.3 \times 10^{-10}$ & $0.53 \pm 0.16$ \\
& Substitution 2 & $0.51 \pm 0.07$ & $6.0 \pm 1.2 \times 10^{-10}$ & $0.48 \pm 0.14$ \\
& Substitution 3 & $0.43 \pm 0.06$ & $5.1 \pm 1.0 \times 10^{-10}$ & $0.41 \pm 0.12$ \\
& Addition 1 & $0.23 \pm 0.02$ & $2.3 \pm 0.5 \times 10^{-10}$ & $0.22 \pm 0.07$ \\
& Addition 2 & $0.13 \pm 0.01$ & $1.2 \pm 0.2 \times 10^{-10}$ & $0.12 \pm 0.04$ \\
& Addition 3 & $7.0 \pm 0.7 \times 10^{-2}$ & $6.8 \pm 1.4 \times 10^{-11}$ & $6.7 \pm 2.0 \times 10^{-2}$ \\
\hline
\end{tabular}

${ }^{*} \mathrm{P}_{\text {dimethylamine }}: 2.4 \pm 0.5 \times 10^{-8}$ torr

Table 2. Pseudo-first order rate constants, second order rate constants, and uptake coefficients for reaction of ammonia with negativelycharged ammonium bisulfate clusters*.

\begin{tabular}{|c|c|c|c|c|}
\hline Cluster & $\begin{array}{r}\text { Reaction } \\
\text { step }\end{array}$ & $\begin{array}{l}\text { Pseudo-first order } \\
\text { rate constant }\left(\mathrm{s}^{-1}\right)\end{array}$ & $\begin{array}{l}\text { Second order rate constant } \\
\qquad\left(\mathrm{cm}^{3} \text { molecule }{ }^{-1} \mathrm{~s}^{-1}\right)\end{array}$ & $\begin{array}{r}\text { Uptake } \\
\text { coefficient, } \gamma\end{array}$ \\
\hline$\left[\left(\mathrm{HSO}_{4}\right)\left(\mathrm{H}_{2} \mathrm{SO}_{4}\right)\right]^{-}$ & Addition & $<5.1 \times 10^{-4}$ & $<1.6 \times 10^{-13}$ & $<8.1 \times 10^{-5}$ \\
\hline$\left[\left(\mathrm{HSO}_{4}\right)\left(\mathrm{H}_{2} \mathrm{SO}_{4}\right)_{2}\right]^{-}$ & Addition & $<3.3 \times 10^{-3}$ & $<1.1 \times 10^{-12}$ & $<5.3 \times 10^{-4}$ \\
\hline$\left[\left(\mathrm{NH}_{4}\right)\left(\mathrm{HSO}_{4}\right)_{2}\left(\mathrm{H}_{2} \mathrm{SO}_{4}\right)_{3}\right]^{-}$ & Addition & $<6.1 \times 10^{-3}$ & $<1.9 \times 10^{-12}$ & $<9.9 \times 10^{-4}$ \\
\hline$\left[\left(\mathrm{NH}_{4}\right)_{2}\left(\mathrm{HSO}_{4}\right)_{3}\left(\mathrm{H}_{2} \mathrm{SO}_{4}\right)_{3}\right]^{-}$ & Addition & $3.1 \pm 0.1 \times 10^{-2}$ & $1.0 \pm 0.2 \times 10^{-11}$ & $5.1 \pm 1.5 \times 10^{-3}$ \\
\hline$\left[\left(\mathrm{NH}_{4}\right)_{3}\left(\mathrm{HSO}_{4}\right)_{4}\left(\mathrm{H}_{2} \mathrm{SO}_{4}\right)_{3}\right]^{-}$ & Addition & $7.1 \pm 0.2 \times 10^{-2}$ & $2.3 \pm 0.5 \times 10^{-11}$ & $1.2 \pm 0.4 \times 10^{-2}$ \\
\hline
\end{tabular}

${ }^{*} \mathrm{P}_{\text {ammonia }}: 1.0 \pm 0.2 \times 10^{-7}$ torr

occurred. With increasing exposure time to dimethylamine, ammonia is displaced by dimethylamine. Next, dimethylamine adds sequentially to the cluster, eventually neutralizing all sulfuric acid molecules to bisulfate. For the $\left[\left(\mathrm{NH}_{4}\right)\left(\mathrm{HSO}_{4}\right)_{2}\left(\mathrm{H}_{2} \mathrm{SO}_{4}\right)_{3}\right]^{-}$cluster, the reactive uptake coefficient (reaction probability, $\gamma$ ) for substitution (i.e. Scheme 1) is $\gamma_{\text {sub }}=0.24 \pm 0.07$. For the sequential addition steps (i.e. Scheme 2), the reactive uptake coefficients are $\gamma_{\text {add } 1}=0.13 \pm 0.04, \gamma_{\text {add } 2}=0.10 \pm 0.03$, and $\gamma_{\mathrm{add} 3}=2.1 \pm 0.6 \times 10^{-2}$.
Table 1 presents pseudo-first order rate constants, second order rate constants, and reactive uptake coefficients for exposure of negatively-charged ammonium bisulfate clusters to dimethylamine. For clusters containing ammonium, substitution steps are fairly fast, with $\gamma_{\text {sub }} \geq 0.24$. These values for substitution are somewhat slower than those observed for positive ions, where $\gamma_{\text {sub }}$ for ammonium ions on the cluster surface is typically greater than 0.50 (Bzdek et al., 2010a, $b, 2011)$. The lower uptake coefficients are probably due to a decrease in the frequency of potentially reactive collisions 
(i.e. collision between the cluster and the amine would need to occur near the ammonium ion, but since fewer ammonium ions are in the cluster, there are more collisions where reaction would not occur). This helps to explain the observed increase in uptake coefficient for substitution as cluster size (and the number of reactive sites) increases. The initial addition step is typically slower than the substitution steps by about a factor of two. The second addition step is slightly slower than the first. However, the final addition step (to neutralize all sulfuric acid to bisulfate) is significantly slower than the first two addition steps for all studied clusters. Future computational work investigating the thermodynamics and structure of these clusters would be beneficial in explaining these experimental observations. Based on the kinetic results, amine substitution for ammonia is facile. Addition is relatively fast and results in further neutralization of the cluster to bisulfate than what can be accomplished by just ammonium.

In addition to examining negatively-charged ammonium bisulfate clusters, we examined the kinetics of dimethylamine addition to two sulfuric acid-bisulfate clusters, specifically $\left[\left(\mathrm{HSO}_{4}\right)\left(\mathrm{H}_{2} \mathrm{SO}_{4}\right)\right]^{-}$and $\left[\left(\mathrm{HSO}_{4}\right)\left(\mathrm{H}_{2} \mathrm{SO}_{4}\right)_{2}\right]^{-}$. Dimethylamine was not observed to add onto the $\left[\left(\mathrm{HSO}_{4}\right)\left(\mathrm{H}_{2} \mathrm{SO}_{4}\right)\right]^{-}$cluster $\left(\gamma_{\mathrm{add}}<9.7 \times 10^{-6}\right)$; however dimethylamine did add to the $\left[\left(\mathrm{HSO}_{4}\right)\left(\mathrm{H}_{2} \mathrm{SO}_{4}\right)_{2}\right]^{-}$ cluster, though at a rate that was an order of magnitude slower than the slowest addition step in the ammoniumcontaining clusters $\left(\gamma_{\text {add }}=1.0 \pm 0.3 \times 10^{-3}\right)$. These observations suggest that for negatively-charged sulfuric acid-bisulfate clusters in this size range, the incorporation of amine is not kinetically favorable. These observations agree with recent computational modeling that suggests similar negatively-charged sulfuric acid-bisulfate clusters containing dimethylamine are not thermodynamically stable (Kurtén et al., 2011).

The reactivity of these same clusters was examined upon exposure to ammonia gas. Table 2 provides pseudo-first order rate constants, second order rate constants, and reactive uptake coefficients for exposure of the three ammonium bisulfate clusters and the two sulfuric acidbisulfate clusters to ammonia. Ammonia added to neither the $\left[\left(\mathrm{HSO}_{4}\right)\left(\mathrm{H}_{2} \mathrm{SO}_{4}\right)\right]^{-}$cluster $\left(\gamma_{\text {add }}<8.1 \times 10^{-5}\right)$ nor the $\left[\left(\mathrm{HSO}_{4}\right)\left(\mathrm{H}_{2} \mathrm{SO}_{4}\right)_{2}\right]^{-}$cluster $\left(\gamma_{\text {add }}<5.3 \times 10^{-4}\right)$. For ammonium-containing clusters, ammonia did not add onto the $\left[\left(\mathrm{NH}_{4}\right)\left(\mathrm{HSO}_{4}\right)_{2}\left(\mathrm{H}_{2} \mathrm{SO}_{4}\right)_{3}\right]^{-}$cluster $\left(\gamma_{\text {add }}<\right.$ $\left.9.9 \times 10^{-4}\right)$, but did add to the $\left[\left(\mathrm{NH}_{4}\right)_{2}\left(\mathrm{HSO}_{4}\right)_{3}\left(\mathrm{H}_{2} \mathrm{SO}_{4}\right)_{3}\right]^{-}$ and $\quad\left[\left(\mathrm{NH}_{4}\right)_{3}\left(\mathrm{HSO}_{4}\right)_{4}\left(\mathrm{H}_{2} \mathrm{SO}_{4}\right)_{3}\right]^{-} \quad$ clusters $\left(\gamma_{\text {add }}=5.1 \pm 1.5 \times 10^{-3}\right.$ and $1.2 \pm 0.4 \times 10^{-2}$, respectively). Addition was slow, so only the first addition step was observed. The addition rates for ammonia to these clusters are more than one order of magnitude slower than those for the first addition of dimethylamine to the dimethylammonium-substituted clusters. The measured kinetics for ammonia addition to the $\left[\left(\mathrm{HSO}_{4}\right)\left(\mathrm{H}_{2} \mathrm{SO}_{4}\right)\right]^{-}$ and $\left[\left(\mathrm{HSO}_{4}\right)\left(\mathrm{H}_{2} \mathrm{SO}_{4}\right)_{2}\right]^{-}$clusters compares favorably with

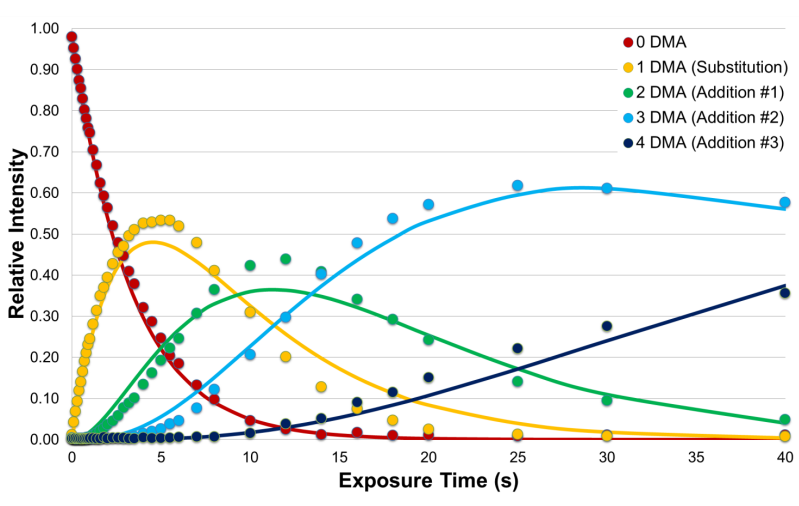

Fig. 3. Reaction profile (symbols) and statistical fit to pseudo-first order kinetics (lines) for exposure of $\left[\left(\mathrm{NH}_{4}\right)\left(\mathrm{HSO}_{4}\right)_{2}\left(\mathrm{H}_{2} \mathrm{SO}_{4}\right)_{3}\right]^{-}$ to dimethylamine gas ( $\mathrm{P}_{\text {dimethylamine }}: 2.4 \pm 0.5 \times 10^{-8}$ torr).

quantum chemical calculations performed previously on these clusters. Ortega et al. (2008) performed calculations that suggest the presence of ammonia is unfavorable in the $\left[\left(\mathrm{HSO}_{4}\right)\left(\mathrm{H}_{2} \mathrm{SO}_{4}\right)\right]^{-}$cluster, which agrees with our kinetics observations, as the uptake coefficient was $<8.1 \times 10^{-5}$. They also predict that the favorability for ammonium in these clusters increases with increasing cluster size, as we have demonstrated here. Our results also compare favorably to Hanson and Eisele (2002), who observed that that uncharged clusters $<300 \mathrm{~m} / z$ did not contain ammonia upon ionization, whereas larger clusters did contain ammonia.

\section{Atmospheric implications}

This study examined the distribution of charged species produced by electrospray of ammonium sulfate and dimethylammonium sulfate solutions in both positive and negative polarities. The ions produced by electrospray give an indication of what charged species might be expected in ambient air within the constraints discussed at the end of Sect. 3.1. Recent advances in instrumentation to measure charged clusters in ambient air permit comparison of the electrospray ionization mass spectra to ambient ion spectra. Specifically, the APi-TOF permits detection of either positively- or negatively-charged ions up to $2000 \mathrm{~m} / \mathrm{z}$ (Junninen et al., 2010; Ehn et al., 2010). APi-TOF analysis of nebulized sulfuric acid mixed with laboratory air (Junninen et al., 2010) yielded a spectrum with some prominent peaks at $\mathrm{m} / \mathrm{z}$ values that correspond to those dominant negativelycharged ammonium bisulfate series observed in this work from electrospray of an ammonium sulfate solution. Ambient measurements of negative ions $<500 \mathrm{~m} / \mathrm{z}$ during the daytime are dominated by sulfuric acid-bisulfate clusters (e.g. $\left[\mathrm{HSO}_{4}\right]^{-},\left[\left(\mathrm{HSO}_{4}\right)\left(\mathrm{H}_{2} \mathrm{SO}_{4}\right)\right]^{-},\left[\left(\mathrm{HSO}_{4}\right)\left(\mathrm{H}_{2} \mathrm{SO}_{4}\right)_{2}\right]^{-}$, and $\left.\left[\left(\mathrm{HSO}_{4}\right)\left(\mathrm{H}_{2} \mathrm{SO}_{4}\right)_{3}\right]^{-}\right)$. Nonetheless, signal from negatively-charged clusters containing ammonium has also 
been detected (e.g. $\left.\left[\left(\mathrm{NH}_{4}\right)\left(\mathrm{HSO}_{4}\right)_{2}\left(\mathrm{H}_{2} \mathrm{SO}_{4}\right)_{2}\right]^{-}\right)($Ehn et al., 2010). These ambient observations confirm the hypothesis that bases will not be observed in low $\mathrm{m} / \mathrm{z}$ negative ion clusters. APi-TOF measurements and the results of these electrospray experiments are also consistent with observations of ambient ions using a flow opposed drift tube coupled to a quadrupole mass analyzer, which indicated that sulfuric acidbisulfate clusters dominate the low $\mathrm{m} / \mathrm{z}$ range (Eisele et al., 2006).

For negative ions, amine-ammonia chemistry will only be evident and important in larger charged clusters $(>400 \mathrm{~m} / \mathrm{z})$, which appear to be much lower in concentration than the low $\mathrm{m} / \mathrm{z}$ clusters and therefore harder to detect. However, as illustrated in Fig. 1, amine-ammonia chemistry is likely to influence even the smallest positive ions. Therefore, these types of clusters should be more evident in ambient positive ion spectra than in ambient negative ion spectra. Ambient positive ion spectra, though, are quite complex (Ehn et al., 2010; Junninen et al., 2010), as there are many other chemical species in the atmosphere competing for a limited amount of charge. Observation of positively-charged ammoniumaminium bisulfate clusters may be obscured by competition with other (non-salt) species for charge or even simply by the vast number of positively-charged ambient species.

The results of our kinetics experiments have important atmospheric implications, especially since many of these charged clusters may be present in ambient air. Charge plays a critical role in the formation of the initial reactive clusters produced by the electrospray process and may affect the reaction rates for the smallest cluster sizes. However, the role of charge diminishes with increasing cluster size. As discussed previously, for both positive and negative ions, the composition appears to converge to ammonium bisulfate at large cluster sizes. Whereas amine substitution for ammonia may or may not be important to the nucleation of new particles, it is likely to impact particle growth in the 1-2 nm size range. Because substitution is nearly collision-limited for the negatively-charged ammonium bisulfate clusters, and because these results agree very well with those of positivelycharged clusters (Bzdek et al., 2010a, b, 2011), ammonium salt clusters in the 1-2 nm size range whether charged or not would be expected to quickly react with amine to form aminium salts upon atmospheric collision of the ammonium salt with the gas-phase amine. Finally, the kinetics of ammonia addition to these clusters is $1-2$ orders of magnitude slower than both mechanisms of dimethylamine incorporation into the cluster (substitution and addition). Therefore, when ambient concentrations of ammonia and amine are comparable, amine chemistry will likely compete favorably with ammonia chemistry.

There are two important limitations to these experiments. First, this work examines the composition and reactivity of charged clusters. However, in the atmosphere, uncharged clusters are thought to dominate over charged clusters (Kulmala et al., 2007; Eisele et al., 2006). The results presented here indicate that the composition of ambient clusters can depend significantly on polarity. Therefore, a major focus of future work should be the composition of uncharged clusters. Whether the composition of the smallest ambient uncharged clusters would be more similar to that of positively-charged clusters, negatively-charged clusters, or neither is an important unanswered question. Second, the role of particulate water is not addressed, as these experiments take place under vacuum. Different experimental methods will be required to address these limitations in future work.

Acknowledgements. B. R. B. acknowledges graduate fellowships from the University of Delaware Center for Critical Zone Research and the American Chemical Society, Division of Analytical Chemistry Fellowship, sponsored by the Society for Analytical Chemists of Pittsburgh. This research was supported by NSF Grant No. CHE-0808972.

Edited by: F. Keutsch

\section{References}

Barsanti, K. C., McMurry, P. H., and Smith, J. N.: The potential contribution of organic salts to new particle growth, Atmos. Chem. Phys., 9, 2949-2957, doi:10.5194/acp-9-2949-2009, 2009.

Berndt, T., Stratmann, F., Sipila, M., Vanhanen, J., Petaja, T., Mikkila, J., Gruner, A., Spindler, G., Mauldin, R. L., Curtius, J., Kulmala, M., and Heintzenberg, J.: Laboratory study on new particle formation from the reaction $\mathrm{OH}+\mathrm{SO}_{2}$ : influence of experimental conditions, $\mathrm{H}_{2} \mathrm{O}$ vapour, $\mathrm{NH}_{3}$ and the amine tert-butylamine on the overall process, Atmos. Chem. Phys., 10, 7101-7116, doi:10.5194/acp-10-7101-2010, 2010.

Bzdek, B. R. and Johnston, M. V.: New particle formation and growth in the troposphere, Anal. Chem., 82, 7871-7878, doi:10.1021/ac100856j, 2010.

Bzdek, B. R., Ridge, D. P., and Johnston, M. V.: Amine exchange into ammonium bisulfate and ammonium nitrate nuclei, Atmos. Chem. Phys., 10, 3495-3503, doi:10.5194/acp-10-3495-2010, 2010a.

Bzdek, B. R., Ridge, D. P., and Johnston, M. V.: Size-dependent reactions of ammonium bisulfate clusters with dimethylamine, J. Phys. Chem. A, 114, 11638-11644, doi:10.1021/jp106363m, 2010b.

Bzdek, B. R., Ridge, D. P., and Johnston, M. V.: Reactivity of methanesulfonic acid salt clusters relevant to marine air, J. Geophys. Res.-Atmos., 116, D03301, doi:03310.01029/02010JD015217, 2011.

Ehn, M., Junninen, H., Petaja, T., Kurten, T., Kerminen, V. M., Schobesberger, S., Manninen, H. E., Ortega, I. K., Vehkamaki, H., Kulmala, M., and Worsnop, D. R.: Composition and temporal behavior of ambient ions in the boreal forest, Atmos. Chem. Phys., 10, 8513-8530, doi:10.5194/acp-10-8513-2010, 2010.

Eisele, F. L., Lovejoy, E. R., Kosciuch, E., Moore, K. F., Mauldin, R. L., Smith, J. N., McMurry, P. H., and Iida, K.: Negative atmospheric ions and their potential role in ion- 
induced nucleation, J. Geophys. Res.-Atmos., 111, D04305, doi:04310.01029/02005jd006568, 2006.

Erupe, M. E., Viggiano, A. A., and Lee, S.-H.: The effect of trimethylamine on atmospheric nucleation involving $\mathrm{H}_{2} \mathrm{SO}_{4}$, Atmos. Chem. Phys., 11, 4767-4775, doi:10.5194/acp-11-47672011, 2011.

Ge, X. L., Wexler, A. S., and Clegg, S. L.: Atmospheric amines - Part I. A review, Atmos. Environ., 45, 524-546, doi:10.1016/j.atmosenv.2010.10.012, 2011.

Hanson, D. R. and Eisele, F. L.: Measurement of prenucleation molecular clusters in the $\mathrm{NH}_{3}, \mathrm{H}_{2} \mathrm{SO}_{4}, \mathrm{H}_{2} \mathrm{O}$ system, J. Geophys. Res.-Atmos., 107, 4158, doi:4110.1029/2001jd001100, 2002.

Junninen, H., Ehn, M., Petäjä, T., Luosujärvi, L., Kotiaho, T., Kostiainen, R., Rohner, U., Gonin, M., Fuhrer, K., Kulmala, M., and Worsnop, D. R.: A high-resolution mass spectrometer to measure atmospheric ion composition, Atmos. Meas. Tech., 3, 10391053, doi:10.5194/amt-3-1039-2010, 2010.

Kuang, C., Riipinen, I., Sihto, S. L., Kulmala, M., McCormick, A. V., and McMurry, P. H.: An improved criterion for new particle formation in diverse atmospheric environments, Atmos. Chem. Phys., 10, 8469-8480, doi:10.5194/acp-10-8469-2010, 2010.

Kulmala, M., Riipinen, I., Sipila, M., Manninen, H. E., Petaja, T., Junninen, H., Dal Maso, M., Mordas, G., Mirme, A., Vana, M., Hirsikko, A., Laakso, L., Harrison, R. M., Hanson, I., Leung, C., Lehtinen, K. E. J., and Kerminen, V. M.: Toward direct measurement of atmospheric nucleation, Science, 318, 89-92, doi:10.1126/science.1144124, 2007.

Kurtén, T., Loukonen, V., Vehkamäki, H., and Kulmala, M.: Amines are likely to enhance neutral and ion-induced sulfuric acid-water nucleation in the atmosphere more effectively than ammonia, Atmos. Chem. Phys., 8, 4095-4103, doi:10.5194/acp8-4095-2008, 2008.

Kurtén, T., Petäjä, T., Smith, J., Ortega, I. K., Sipila, M., Junninen, H., Ehn, M., Vehkamaki, H., Mauldin, L., Worsnop, D. R., and Kulmala, M.: The effect of $\mathrm{H}_{2} \mathrm{SO}_{4}$-amine clustering on chemical ionization mass spectrometry (CIMS) measurements of gas-phase sulfuric acid, Atmos. Chem. Phys., 11, 3007-3019, doi:10.5194/acp-11-3007-2011, 2011.

Makela, J. M., Yli-Koivisto, S., Hiltunen, V., Seidl, W., Swietlicki, E., Teinila, K., Sillanpaa, M., Koponen, I. K., Paatero, J., Rosman, K., and Hameri, K.: Chemical composition of aerosol during particle formation events in boreal forest, Tellus, Ser. B, 53, 380-393, 2001.

Merikanto, J., Spracklen, D. V., Mann, G. W., Pickering, S. J., and Carslaw, K. S.: Impact of nucleation on global CCN, Atmos. Chem. Phys., 9, 8601-8616, doi:10.5194/acp-9-8601-2009, 2009.

Ortega, I. K., Kurtén, T., Vehkamäki, H., and Kulmala, M.: The role of ammonia in sulfuric acid ion induced nucleation, Atmos. Chem. Phys., 8, 2859-2867, doi:10.5194/acp-8-2859-2008, 2008.
Oss, M., Kruve, A., Herodes, K., and Leito, I.: Electrospray ionization efficiency scale of organic compounds, Anal. Chem., 82, 2865-2872, doi:10.1021/ac902856t, 2010.

Qiu, C., Wang, L., Lal, V., Khalizov, A. F., and Zhang, R. Y.: Heterogeneous reactions of alkylamines with ammonium sulfate and ammonium bisulfate, Environ. Sci. Technol., 45, 4748-4755, doi:10.1021/es1043112, 2011.

Ridge, D. P.: Ion-Molecule Collision Theory, in: The Encyclopedia of Mass Spectrometry, edited by: Armentrout, P. B., Elsevier, San Diego, CA, 1-8, 2003.

Smith, J. N., Dunn, M. J., VanReken, T. M., Iida, K., Stolzenburg, M. R., McMurry, P. H., and Huey, L. G.: Chemical composition of atmospheric nanoparticles formed from nucleation in Tecamac, Mexico: Evidence for an important role for organic species in nanoparticle growth, Geophys. Res. Lett., 35, L04808, doi:04810.01029/02007gl032523, 2008.

Smith, J. N., Barsanti, K. C., Friedli, H. R., Ehn, M., Kulmala, M., Collins, D. R., Scheckman, J. H., Williams, B. J., and McMurry, P. H.: Observations of aminium salts in atmospheric nanoparticles and possible climatic implications, Proc. Natl. Acad. Sci. U.S.A., 107, 6634-6639, doi:10.1073/pnas.0912127107, 2010.

Spracklen, D. V., Carslaw, K. S., Kulmala, M., Kerminen, V. M., Sihto, S. L., Riipinen, I., Merikanto, J., Mann, G. W., Chipperfield, M. P., Wiedensohler, A., Birmili, W., and Lihavainen, H.: Contribution of particle formation to global cloud condensation nuclei concentrations, Geophys. Res. Lett., 35, L06808, doi:06810.01029/02007g1033038, 2008.

Wang, L., Khalizov, A. F., Zheng, J., Xu, W., Ma, Y., Lal, V., and Zhang, R.: Atmospheric nanoparticles formed from heterogeneous reactions of organics, Nat. Geosci., 3, 238-242, doi:10.1038/ngeo778, 2010a.

Wang, L., Lal, V., Khalizov, A. F., and Zhang, R.: Heterogeneous chemistry of alkylamines with sulfuric acid: Implications for atmospheric formation of alkylaminium sulfates, Environ. Sci. Technol., 44, 2461-2465, doi:10.1021/es9036868, 2010b.

Zhao, J., Eisele, F. L., Titcombe, M., Kuang, C., and McMurry, P. H.: Chemical ionization mass spectrometric measurements of atmospheric neutral clusters using the cluster-CIMS, J. Geophys. Res.-Atmos., 115, D08205, doi:08210.01029/02009JD012606, 2010.

Zordan, C. A., Pennington, M. R., and Johnston, M. V.: Elemental composition of nanoparticles with the Nano Aerosol Mass Spectrometer, Anal. Chem., 82, 8034-8038, doi:10.1021/ac101700q, 2010. 